\title{
Award-winning papers in 2017
}

Papers published in Bridge Engineering are eligible for awards from the Institution of Civil Engineers (ICE). Papers from any of the ICE journals can be nominated for several awards. In addition, each journal has awards dedicated to their specific subject area.

On Monday 8 October 2018, ICE president Robert Mair presented an award to the following paper published in Bridge Engineering in 2017. The Editorial Panel nominated their best papers and an awards committee chaired by Nigel Wright allocated the awards.

\section{John Henry Garood King Medal}

The John Henry Garood King Medal, awarded to the best paper on tunnels, soil mechanics or bridges, was awarded to Hendy et al. (2017).

\section{Abstract}

Walton Bridge comprises a steel thrust arch with pad foundations supporting a steel-concrete composite ladder deck. The arch ribs have parabolic profile and varying hexagonal cross-section, tapering from springing points to crown, and span $96.1 \mathrm{~m}$. The total rise of the arch is $14.77 \mathrm{~m}$ with a span to rise ratio of 6.5 . The bridge deck is suspended from the arch by bar-type hangers. Continuous end spans carry the bridge deck between the arch and end abutments, which are full-height

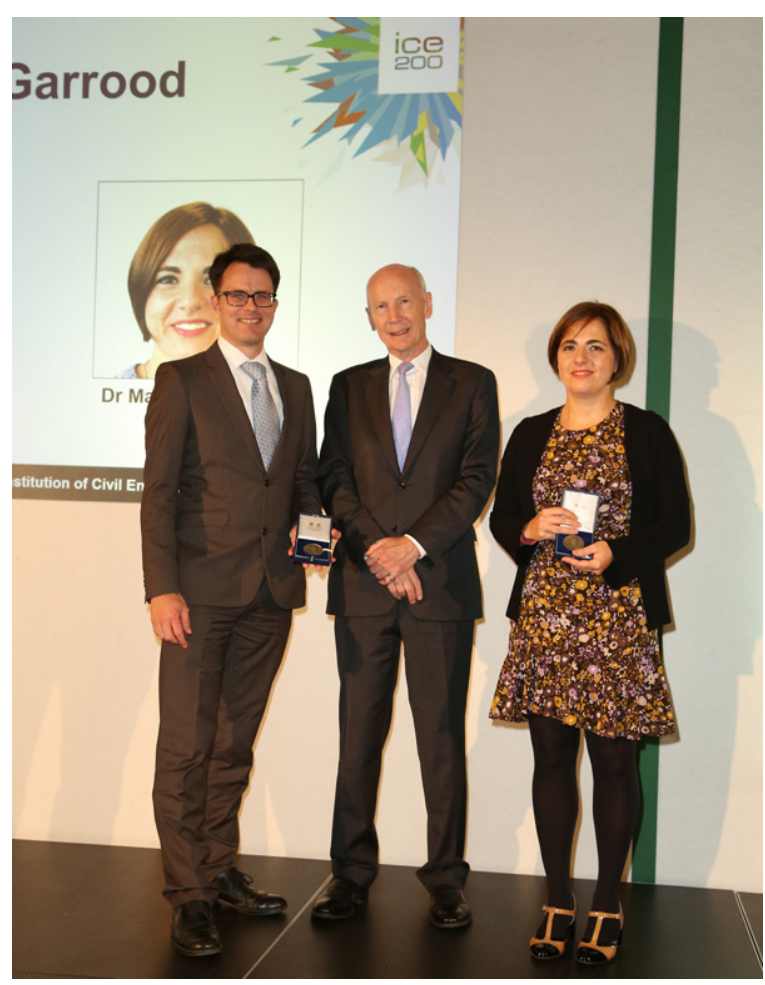

Winners of the John Henry Garood King Prize, David A. Smith and Manuela Chiarello, with ICE President Robert Mair (centre) reinforced concrete. This paper discusses the method of design employed including the impact of construction methodology and environmental constraints, together with analysis of aerodynamic effects. It focuses on a number of innovations that were introduced and challenges that were resolved. Two key issues had to be addressed. First, the arch design utilising plastic section properties with reductions to account for the continuously curved steel plating making up the arch ribs. This required local non-linear analysis to demonstrate that the curved arch plating had similar, but slightly reduced, strength and ductility to an equivalent flat plate with the same width and thickness. Hand calculation methods were developed from the results of the analysis. Second, the design and specification of bar-type arch hangers for brittle fracture and fatigue, with insufficient industry guidance on either subject: there is little codified guidance on toughness requirements for bars or on fatigue testing taking angular tolerances at end connections into account, arising both from initial setting-out tolerances and displacements in service from variable actions including temperature effects.

\section{Mokshagundam Visvesvaraya Prize}

The Mokshagundam Visvesvaraya Prize, presented to the best two papers received on a subject connected with works carried out outside the British Isles, was awarded to Abbas et al. (2017).

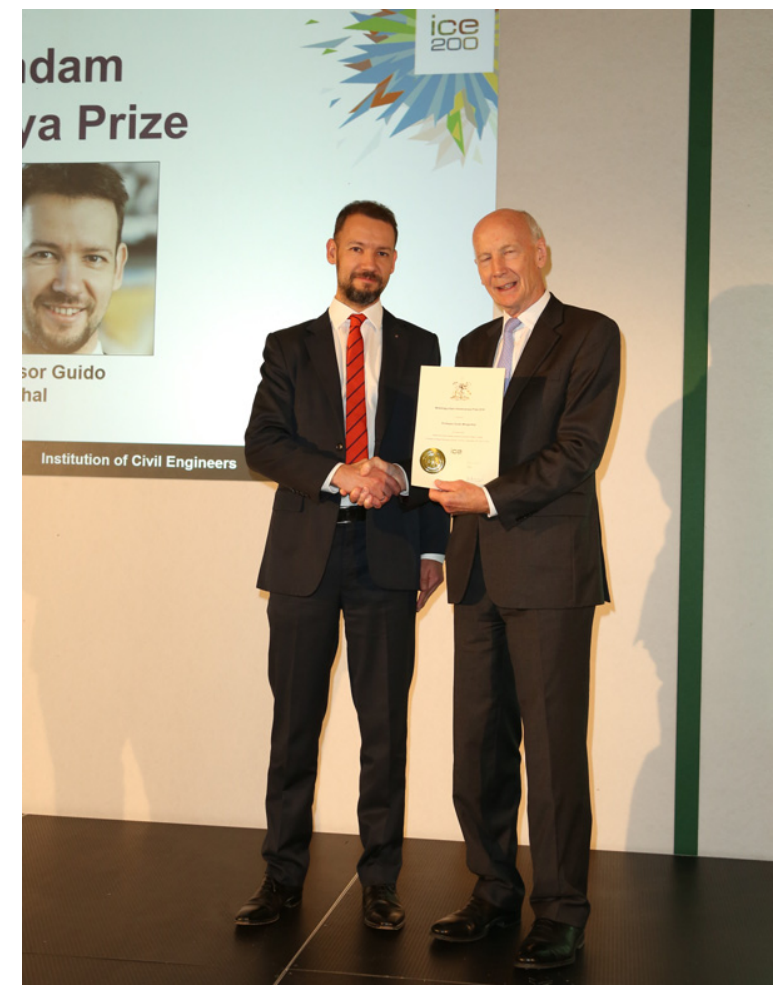

Winner of the Mokshagundam Visvesvaraya Prize, Guido Morgenthal (left), with ICE President Robert Mair 
between wind tunnel testing and CFD is provided. Finally, this paper also describes the engineering solutions adopted as countermeasures to prevent flutter instabilities.

Predicting the phenomenon of aerodynamic instability is essential for the analysis and design of long-span cable-supported bridges. This paper reviews the history and development of aerodynamic analysis techniques and state-of-the-art numerical and experimental methods for flutter stability analysis. A discussion of the flutter phenomenon is followed by a literature review. This study provides a perspective on self-excited aerodynamic force models, identification of aerodynamic derivatives and methods for determining aerodynamic instability of long-span bridges in two dimensions and three dimensions. Computational fluid dynamics (CFD) techniques for modelling the flow past bluff bodies are also covered

Different model combination techniques are presented, utilising analytical, numerical and experimental approaches to predict the flutter limit. The effect of different parameters on the flutter stability limit is also highlighted. Furthermore, an overview of the complementary relationship
Abbas T, Kavrakov I and Morgenthal G (2017) Methods for flutter stability analysis of long-span bridges: a review. Proceedings of the Institution of Civil Engineers - Bridge Engineering 170(4): 271-310, https://doi.org/10.1680/jbren.15.00039.

Hendy CR, Smith DA and Chiarello M (2017) Walton Bridge - a new arch bridge over the River Thames, UK. Proceedings of the Institution of Civil Engineers - Bridge Engineering 170(2): 102-115, https://doi.org/10.1680/jbren.15.00044.

\section{REFERENCES}

